\title{
Convergence Theorems for Total Asymptotically Nonexpansive Mappings in Hyperbolic Spaces
}

\author{
Liang-cai Zhao, ${ }^{1}$ Shih-sen Chang, ${ }^{2}$ and Xiong Rui Wang ${ }^{1}$ \\ ${ }^{1}$ Institute of Mathematics, Yibin University, Yibin, Sichuan 644000, China \\ ${ }^{2}$ College of Statistics and Mathematics, Yunnan University of Finance and Economics, Kunming, Yunnan 650221, China \\ Correspondence should be addressed to Shih-sen Chang; changss2013@aliyun.com
}

Received 15 July 2013; Accepted 30 September 2013

Academic Editor: Zhenyu Huang

Copyright (c) 2013 Liang-cai Zhao et al. This is an open access article distributed under the Creative Commons Attribution License, which permits unrestricted use, distribution, and reproduction in any medium, provided the original work is properly cited.

The purpose of this paper is to introduce the concept of total asymptotically nonexpansive mappings and to prove some $\Delta$ convergence theorems of the iteration process for this kind of mappings in the setting of hyperbolic spaces. The results presented in the paper extend and improve some recent results announced in the current literature.

\section{Introduction and Preliminaries}

Most of the problems in various disciplines of science are nonlinear in nature whereas fixed point theory proposed in the setting of normed linear spaces or Banach spaces majorly depends on the linear structure of the underlying spaces. A nonlinear framework for fixed point theory is a metric space embedded with a "convex structure." The class of hyperbolic spaces, nonlinear in nature, is a general abstract theoretic setting with rich geometrical structure for metric fixed point theory. The study of hyperbolic spaces has been largely motivated and dominated by questions about hyperbolic groups, one of the main objects of study in geometric group theory.

Throughout this paper, we work in the setting of hyperbolic spaces introduced by Kohlenbach [1], defined below, which is more restrictive than the hyperbolic type introduced in [2] and more general than the concept of hyperbolic space in [3].

A hyperbolic space is a metric space $(X, d)$ together with a mapping $W: X^{2} \times[0,1] \rightarrow X$ satisfying

(i) $d(u, W(x, y, \alpha)) \leq(1-\alpha) d(u, x)+\alpha d(u, y)$;

(ii) $d(W(x, y, \alpha), W(x, y, \beta))=|\alpha-\beta| d(x, y)$;

(iii) $W(x, y, \alpha)=W(y, x,(1-\alpha))$;

(iv) $d(W(x, z, \alpha), W(y, w, \alpha)) \leq(1-\alpha) d(x, y)+\alpha d(z, w)$, for all $x, y, z, w \in X$ and $\alpha, \beta \in[0,1]$. A nonempty subset $K$ of a hyperbolic space $X$ is convex if $W(x, y, \alpha) \in K$ for all $x, y \in K$ and $\alpha \in[0,1]$. The class of hyperbolic spaces contains normed spaces and convex subsets thereof, the Hilbert ball equipped with the hyperbolic metric [4], Hadamard manifolds, and CAT(0) spaces in the sense of Gromov (see [5]).

A hyperbolic space is uniformly convex [6] if for any $r>$ 0 and $\epsilon \in(0,2]$ there exists a $\delta \in(0,1]$, such that, for all $u, x, y \in X$, we have

$$
d\left(W\left(x, y, \frac{1}{2}\right), u\right) \leq(1-\delta) r
$$

provided $d(x, u) \leq r, d(y, u) \leq r$ and $d(x, y) \geq \epsilon r$.

A map $\eta:(0, \infty) \times(0,2] \rightarrow(0,1]$, which provides such a $\delta=\eta(r, \epsilon)$ for given $r>0$ and $\epsilon \in(0,2]$, is known as a modulus of uniform convexity of $X$. We call $\eta$ monotone if it decreases with $r$ (for a fixed $\epsilon$ ), that is, for all $\epsilon>0$, for all $r_{2} \geq r_{1}>0\left(\eta\left(r_{2}, \epsilon\right) \leq \eta\left(r_{1}, \epsilon\right)\right)$.

In the sequel, let $(X, d)$ be a metric space and let $K$ be a nonempty subset of $X$. We will denote the fixed point set of a mapping $T$ by $F(T)=\{x \in K: T x=x\}$.

A mapping $T: K \rightarrow K$ is said to be nonexpansive, if

$$
d(T x, T y) \leq d(x, y), \quad \forall x, y \in K .
$$


A mapping $T: K \rightarrow K$ is said to be asymptotically nonexpansive if there exists a sequence $\left\{k_{n}\right\} \subset[1, \infty)$ with $k_{n} \rightarrow 1$ such that

$$
d\left(T^{n} x, T^{n} y\right) \leq k_{n} d(x, y), \quad \forall n \geq 1, x, y \in K .
$$

A mapping $T: K \rightarrow K$ is said to be uniformly $L^{-}$ Lipschitzian if there exists a constant $L>0$ such that

$$
d\left(T^{n} x, T^{n} y\right) \leq L d(x, y), \quad \forall n \geq 1, x, y \in K .
$$

Definition 1. A mapping $T: K \rightarrow K$ is said to be $\left(\left\{\mu_{n}\right\},\left\{\xi_{n}\right\}, \phi\right)$-total asymptotically nonexpansive, if there exist nonnegative sequences $\left\{\mu_{n}\right\},\left\{\xi_{n}\right\}$ with $\mu_{n} \rightarrow 0, \xi_{n} \rightarrow 0$ and a strictly increasing continuous function $\phi:[0, \infty) \rightarrow[0, \infty)$ with $\phi(0)=0$ such that

$$
\begin{array}{r}
d\left(T^{n} x, T^{n} y\right) \leq d(x, y)+\mu_{n} \phi(d(x, y))+\xi_{n}, \\
\forall n \geq 1, x, y \in K .
\end{array}
$$

Remark 2. From the definitions, it is clear that each nonexpansive mapping is an asymptotically nonexpansive mapping with a sequence $\left\{k_{n}=1\right\}$ and each asymptotically nonexpansive mapping is a $\left(\left\{\mu_{n}\right\},\left\{\xi_{n}\right\}, \phi\right)$-total asymptotically nonexpansive mapping with $\xi_{n}=0, \mu_{n}=k_{n}-1, n \geq 1$ and $\phi(t)=t, t \geq 0$.

The existence of fixed points of various nonlinear mappings has relevant applications in many branches of nonlinear analysis and topology. On the other hand, there are certain situations where it is difficult to derive conditions for the existence of fixed points for certain types of nonlinear mappings. It is worth mentioning that fixed point theory for nonexpansive mappings, a limit case of a contraction mapping when the Lipschitz constant is allowed to be 1, requires tools far beyond from metric fixed point theory. Iteration schemas are the only main tool for analysis of generalized nonexpansive mappings. Fixed point theory has a computational flavor as one can define effective iteration schemas for the computation of fixed points of various nonlinear mappings. The problem of finding a common fixed point of some nonlinear mappings acting on a nonempty convex domain often arises in applied mathematics.

The purpose of this paper is to introduce the concept of total asymptotically nonexpansive mappings and to prove some $\Delta$-convergence theorems of the iteration process for the approximation of total asymptotically nonexpansive mappings in hyperbolic spaces. The results presented in the paper extend and improve some recent results given in [6-18].

In order to define the concept $\Delta$-convergence in the general setup of hyperbolic spaces, we first collect some basic concepts.

Let $\left\{x_{n}\right\}$ be a bounded sequence in a hyperbolic space $X$. For $x \in X$, we define a continuous functional $r\left(\cdot,\left\{x_{n}\right\}\right): X \rightarrow$ $[0, \infty)$ by

$$
r\left(x,\left\{x_{n}\right\}\right)=\limsup _{n \rightarrow \infty} d\left(x, x_{n}\right) .
$$

The asymptotic radius $r\left(\left\{x_{n}\right\}\right)$ of $\left\{x_{n}\right\}$ is given by

$$
r\left(\left\{x_{n}\right\}\right)=\inf \left\{r\left(x,\left\{x_{n}\right\}\right): x \in X\right\} .
$$

The asymptotic center $A_{k}\left(\left\{x_{n}\right\}\right)$ of a bounded sequence $\left\{x_{n}\right\}$ with respect to $K \subset X$ is the set

$$
A_{K}\left(\left\{x_{n}\right\}\right)=\left\{x \in X: r\left(x,\left\{x_{n}\right\}\right) \leq r\left(y,\left\{x_{n}\right\}\right), \forall y \in K\right\} .
$$

This is the set of minimizers of the functional $r\left(\cdot,\left\{x_{n}\right\}\right)$. If the asymptotic center is taken with respect to $X$, then it is simply denoted by $A\left(\left\{x_{n}\right\}\right)$. It is known that uniformly convex Banach spaces and CAT $(0)$ spaces enjoy the property that "bounded sequences have unique asymptotic centers with respect to closed convex subsets." The following lemma is due to Leuştean [19] and ensures that this property also holds in a complete uniformly convex hyperbolic space.

Lemma 3 (see [19]). Let $(X, d, W)$ be a complete uniformly convex hyperbolic space with monotone modulus of uniform convexity. Then, every bounded sequence $\left\{x_{n}\right\}$ in $X$ has a unique asymptotic center with respect to any nonempty closed convex subset $K$ of $X$.

Recall that a sequence $\left\{x_{n}\right\}$ in $X$ is said to $\Delta$-converge to $x \in X$ if $x$ is the unique asymptotic center of $\left\{u_{n}\right\}$ for every subsequence $\left\{u_{n}\right\}$ of $\left\{x_{n}\right\}$. In this case, we write $\Delta-\lim _{n \rightarrow \infty} x_{n}=$ $x$ and call $x$ the $\Delta$-limit of $\left\{x_{n}\right\}$.

A mapping $T: K \rightarrow K$ is semicompact if every bounded sequence $\left\{x_{n}\right\} \subset K$, satisfying $d\left(x_{n}, T x_{n}\right) \rightarrow 0$, has a convergent subsequence.

Lemma 4 (see [8]). Let $\left\{a_{n}\right\},\left\{b_{n}\right\}$, and $\left\{\delta_{n}\right\}$ be sequences of nonnegative real numbers satisfying

$$
a_{n+1} \leq\left(1+\delta_{n}\right) a_{n}+b_{n}, \quad \forall n \geq 1 .
$$

If $\sum_{n=1}^{\infty} \delta_{n}<\infty$ and $\sum_{n=1}^{\infty} b_{n}<\infty$, then the limit $\lim _{n \rightarrow \infty} a_{n}$ exists. If there exists a subsequence $\left\{a_{n_{i}}\right\} \subset\left\{a_{n}\right\}$ such that $a_{n_{i}} \rightarrow$ 0 , then $\lim _{n \rightarrow \infty} a_{n}=0$.

Lemma 5 (see [11]). Let $(X, d, W)$ be a uniformly convex hyperbolic space with monotone modulus of uniform convexity $\eta$. Let $x \in X$ and $\left\{\alpha_{n}\right\}$ be a sequence in $[a, b]$ for some $a, b \in$ $(0,1)$. If $\left\{x_{n}\right\}$ and $\left\{y_{n}\right\}$ are sequences in $X$ such that

$$
\begin{gathered}
\limsup _{n \rightarrow \infty} d\left(x_{n}, x\right) \leq c, \quad \limsup _{n \rightarrow \infty} d\left(y_{n}, x\right) \leq c, \\
\lim _{n \rightarrow \infty} d\left(W\left(x_{n}, y_{n}, \alpha_{n}\right), x\right)=c
\end{gathered}
$$

for some $c \geq 0$, then $\lim _{n \rightarrow \infty} d\left(x_{n}, y_{n}\right)=0$.

Lemma 6 (see [11]). Let $K$ be a nonempty closed convex subset of uniformly convex hyperbolic space and $\left\{x_{n}\right\}$ a bounded sequence in $K$ such that $A\left(\left\{x_{n}\right\}\right)=\{y\}$ and $r\left(\left\{x_{n}\right\}\right)=\rho$. If $\left\{y_{m}\right\}$ is another sequence in $K$ such that $\lim _{m \rightarrow \infty} r\left(y_{m},\left\{x_{n}\right\}\right)=\rho$, then $\lim _{m \rightarrow \infty} y_{m}=y$.

\section{Main Results}

Theorem 7. Let $K$ be a nonempty closed convex subset of a complete uniformly convex hyperbolic space $X$ with monotone modulus of uniform convexity $\eta$. Let $T_{i}: K \rightarrow K, i=$ 1,2 , be uniformly $L_{i}$-Lipschitzian and $\left(\left\{\mu_{i n}\right\},\left\{\xi_{\text {in }}\right\}, \phi_{i}\right)$-total 
asymptotically nonexpansive mappings with sequences $\left\{\mu_{i n}\right\}$ and $\left\{\xi_{\text {in }}\right\}$ satisfying $\lim _{n \rightarrow \infty} \mu_{\text {in }}=0, \lim _{n \rightarrow \infty} \xi_{\text {in }}=0$, and strictly increasing function $\phi_{i}:[0, \infty) \rightarrow[0, \infty)$ with $\phi_{i}(0)=$ $0, i=1,2$. Assume that $F:=\bigcap_{i=1}^{2} F\left(T_{i}\right) \neq \emptyset$, and for arbitrarily chosen $x_{1} \in K,\left\{x_{n}\right\}$ is defined as follows:

$$
\begin{gathered}
x_{n+1}=W\left(x_{n}, T_{1}^{n} y_{n}, \alpha_{n}\right), \\
y_{n}=W\left(x_{n}, T_{2}^{n} x_{n}, \beta_{n}\right),
\end{gathered}
$$

where $\left\{\mu_{i n}\right\},\left\{\xi_{i n}\right\}, \phi_{i}, i=1,2,\left\{\alpha_{n}\right\}$, and $\left\{\beta_{n}\right\}$ satisfy the following conditions:

(1) $\sum_{n=1}^{\infty} \mu_{\text {in }}<\infty, \sum_{n=1}^{\infty} \xi_{\text {in }}<\infty, i=1,2$;

(2) there exist constants $a, b \in(0,1)$ with $0<b(1-a) \leq$ $1 / 2$ such that $\left\{\alpha_{n}\right\} \subset[a, b]$ and $\left\{\beta_{n}\right\} \subset[a, b]$;

(3) there exist a constant $M^{*}>0$ such that $\phi_{i}(r) \leq$ $M^{*} r, r>0, i=1,2$.

Then, the sequence $\left\{x_{n}\right\}$ defined by (11) $\Delta$-converges to a common fixed point of $F:=\bigcap_{i=1}^{2} F\left(T_{i}\right)$.

Proof. The proof of Theorem 7 is divided into four steps.

Step 1. First, we prove that $\lim _{n \rightarrow \infty} d\left(x_{n}, p\right)$ exists for each $p \in$ F.

Set $\mu_{n}=\max \left\{\mu_{1 n}, \mu_{2 n}\right\}, \xi_{n}=\max \left\{\xi_{1 n}, \xi_{2 n}\right\}$, and $L=$ $\max \left\{L_{1}, L_{2}\right\}$. Since $\sum_{n=1}^{\infty} \mu_{\text {in }}<\infty, \sum_{n=1}^{\infty} \xi_{\text {in }}<\infty, i=1,2$, $\sum_{n=1}^{\infty} \mu_{n}<\infty, \sum_{n=1}^{\infty} \xi_{n}<\infty$. For any $p \in F\left(T_{1}\right) \cap F\left(T_{2}\right)$, by (11) we have

$$
\begin{aligned}
& d\left(x_{n+1}, p\right) \\
& =d\left(W\left(x_{n}, T_{1}^{n} y_{n}, \alpha_{n}\right), p\right) \\
& \leq\left(1-\alpha_{n}\right) d\left(x_{n}, p\right)+\alpha_{n} d\left(T_{1}^{n} y_{n}, p\right) \\
& \leq\left(1-\alpha_{n}\right) d\left(x_{n}, p\right)+\alpha_{n}\left[d\left(y_{n}, p\right)+\mu_{n} \phi_{1}\left(d\left(y_{n}, p\right)\right)+\xi_{n}\right] \\
& \leq\left(1-\alpha_{n}\right) d\left(x_{n}, p\right)+\alpha_{n}\left[\left(1+\mu_{n} M^{*}\right) d\left(y_{n}, p\right)+\xi_{n}\right]
\end{aligned}
$$

where

$$
\begin{aligned}
& d\left(y_{n}, p\right) \\
& =d\left(W\left(x_{n}, T_{2}^{n} x_{n}, \beta_{n}\right), p\right) \\
& \leq\left(1-\beta_{n}\right) d\left(x_{n}, p\right)+\beta_{n} d\left(T_{2}^{n} x_{n}, p\right) \\
& \leq\left(1-\beta_{n}\right) d\left(x_{n}, p\right)+\beta_{n}\left[d\left(x_{n}, p\right)+\mu_{n} \phi_{2}\left(d\left(x_{n}, p\right)\right)+\xi_{n}\right] \\
& \leq\left(1-\beta_{n}\right) d\left(x_{n}, p\right)+\beta_{n}\left[\left(1+\mu_{n} M^{*}\right) d\left(x_{n}, p\right)+\xi_{n}\right] \\
& \leq\left(1+\beta_{n} \mu_{n} M^{*}\right) d\left(x_{n}, p\right)+\beta_{n} \xi_{n} .
\end{aligned}
$$

Substituting (13) into (12), we have

$$
\begin{aligned}
& d\left(x_{n+1}, p\right) \\
& \leq\left(1-\alpha_{n}\right) d\left(x_{n}, p\right) \\
& \quad+\alpha_{n}\left[\left(1+\mu_{n} M^{*}\right)\left(\left(1+\beta_{n} \mu_{n} M^{*}\right) d\left(x_{n}, p\right)+\beta_{n} \xi_{n}\right)+\xi_{n}\right] \\
& \leq\left[1+\left(1+\beta_{n}+\beta_{n} \mu_{n} M^{*}\right) \alpha_{n} \mu_{n} M^{*}\right] d\left(x_{n}, p\right) \\
& \quad+\left(1+\beta_{n}+\beta_{n} \mu_{n} M^{*}\right) \alpha_{n} \xi_{n} .
\end{aligned}
$$

Applying Lemma 4 to the inequality, we get that $\lim _{n \rightarrow \infty} d\left(x_{n}, p\right)$ exist for $p \in F\left(T_{1}\right) \cap F\left(T_{2}\right)$.

Step 2. We show that $\lim _{n \rightarrow \infty} d\left(x_{n}, T_{1} x_{n}\right)$ = $\lim _{n \rightarrow \infty} d\left(x_{n}, T_{2} x_{n}\right)=0$.

For each $p \in F\left(T_{1}\right) \cap F\left(T_{2}\right)$, from the proof of Step 1, we know that $\lim _{n \rightarrow \infty} d\left(x_{n}, p\right)$ exists. We may assume that $\lim _{n \rightarrow \infty} d\left(x_{n}, p\right)=c \geq 0$. The case $c=0$ is trivial. Next, we deal with the case $c>0$. From (13), we have

$$
d\left(y_{n}, p\right) \leq\left(1+\beta_{n} \mu_{n} M^{*}\right) d\left(x_{n}, p\right)+\beta_{n} \xi_{n} .
$$

Taking limsup on both sides in (15), we have

$$
\limsup _{n \rightarrow \infty} d\left(y_{n}, p\right) \leq c
$$

In addition, since

$$
\begin{aligned}
d\left(T_{1}^{n} y_{n}, p\right) & \leq d\left(y_{n}, p\right)+\mu_{n} \phi_{1}\left(d\left(y_{n}, p\right)\right)+\xi_{n} \\
& \leq\left(1+\mu_{n} M^{*}\right) d\left(y_{n}, p\right)+\xi_{n},
\end{aligned}
$$

we have

$$
\limsup _{n \rightarrow \infty} d\left(T_{1}^{n} y_{n}, p\right) \leq c
$$

Since $\lim _{n \rightarrow \infty} d\left(x_{n+1}, p\right)=c$, it is easy to prove that

$$
\lim _{n \rightarrow \infty} d\left(W\left(x_{n}, T_{1}^{n} y_{n}, \alpha_{n}\right), p\right)=c .
$$

It follows from Lemma 5 that

$$
\lim _{n \rightarrow \infty} d\left(x_{n}, T_{1}^{n} y_{n}\right)=0 .
$$

On the other hand, since

$$
\begin{aligned}
d\left(x_{n}, p\right) & \leq d\left(x_{n}, T_{1}^{n} y_{n}\right)+d\left(T_{1}^{n} y_{n}, p\right) \\
& \leq d\left(x_{n}, T_{1}^{n} y_{n}\right)+d\left(y_{n}, p\right)+\mu_{n} \phi_{1}\left(d\left(y_{n}, p\right)\right)+\xi_{n} \\
& \leq d\left(x_{n}, T_{1}^{n} y_{n}\right)+\left(1+\mu_{n} M^{*}\right) d\left(y_{n}, p\right)+\xi_{n},
\end{aligned}
$$

we have $\liminf _{n \rightarrow \infty} d\left(y_{n}, p\right) \geq c$. Combined with (16), it yields that

$$
\lim _{n \rightarrow \infty} d\left(y_{n}, p\right)=c
$$


This implies that

$$
\lim _{n \rightarrow \infty} d\left(W\left(x_{n}, T_{2}^{n} x_{n}, \beta_{n}\right), p\right)=c .
$$

Since

$$
\begin{aligned}
d\left(T_{2}^{n} x_{n}, p\right) & \leq d\left(x_{n}, p\right)+\mu_{n} \phi_{2}\left(d\left(x_{n}, p\right)\right)+\xi_{n} \\
& \leq\left(1+\mu_{n} M^{*}\right) d\left(x_{n}, p\right)+\xi_{n}
\end{aligned}
$$

we have

$$
\limsup _{n \rightarrow \infty} d\left(T_{2}^{n} x_{n}, p\right) \leq c
$$

So, it follows from (25) and Lemma 5 that

$$
\lim _{n \rightarrow \infty} d\left(x_{n}, T_{2}^{n} x_{n}\right)=0
$$

Observe that

$$
\begin{aligned}
& d\left(x_{n}, T_{1}^{n} x_{n}\right) \\
& \quad \leq d\left(x_{n}, T_{1}^{n} y_{n}\right)+d\left(T_{1}^{n} y_{n}, T_{1}^{n} x_{n}\right) \\
& \quad \leq d\left(x_{n}, T_{1}^{n} y_{n}\right)+d\left(y_{n}, x_{n}\right)+\mu_{n} \phi_{1}\left(d\left(y_{n}, x_{n}\right)\right)+\xi_{n} \\
& \quad=d\left(x_{n}, T_{1}^{n} y_{n}\right)+\left(1+\mu_{n} M^{*}\right) d\left(y_{n}, x_{n}\right)+\xi_{n},
\end{aligned}
$$

where

$$
d\left(y_{n}, x_{n}\right)=d\left(W\left(x_{n}, T_{2}^{n} x_{n}, \beta_{n}\right), x_{n}\right) \leq \beta_{n} d\left(x_{n}, T_{2}^{n} x_{n}\right) .
$$

It follows from (26) that

$$
\lim _{n \rightarrow \infty} d\left(y_{n}, x_{n}\right)=0 .
$$

Thus, from (20), (27), and (29), we have

$$
\lim _{n \rightarrow \infty} d\left(x_{n}, T_{1}^{n} x_{n}\right)=0 .
$$

In addition, since

$$
\begin{aligned}
d\left(x_{n+1}, x_{n}\right) & =d\left(W\left(x_{n}, T_{1}^{n} y_{n}, \alpha_{n}\right), x_{n}\right) \\
& \leq \alpha_{n} d\left(x_{n}, T_{1}^{n} y_{n}\right)
\end{aligned}
$$

from (20), we have

$$
\lim _{n \rightarrow \infty} d\left(x_{n+1}, x_{n}\right)=0 .
$$

Finally, since

$$
\begin{aligned}
d\left(x_{n}, T_{1} x_{n}\right) \leq & d\left(x_{n}, x_{n+1}\right)+d\left(x_{n+1}, T_{1}^{n+1} x_{n+1}\right) \\
& +d\left(T_{1}^{n+1} x_{n+1}, T_{1}^{n+1} x_{n}\right)+d\left(T_{1}^{n+1} x_{n}, T_{1} x_{n}\right) \\
\leq & (1+L) d\left(x_{n}, x_{n+1}\right)+d\left(x_{n+1}, T_{1}^{n+1} x_{n+1}\right) \\
& +\operatorname{Ld}\left(T_{1}^{n} x_{n}, x_{n}\right)
\end{aligned}
$$

it follows from (30) and (32) that

$$
\lim _{n \rightarrow \infty} d\left(x_{n}, T_{1} x_{n}\right)=0 .
$$

Similarly, we also can show that

$$
\lim _{n \rightarrow \infty} d\left(x_{n}, T_{2} x_{n}\right)=0
$$

Step 3. Now we prove that the sequence $\left\{x_{n}\right\} \Delta$-converges to a common fixed point of $F\left(T_{1}\right) \cap F\left(T_{2}\right)$.

In fact, since, for each $p \in F, \lim _{n \rightarrow \infty} d\left(x_{n}, p\right)$ exists, this implies that the sequence $\left\{d\left(x_{n}, p\right)\right\}$ is bounded, so is the sequence $\left\{x_{n}\right\}$. Hence, by virtue of Lemma $3,\left\{x_{n}\right\}$ has a unique asymptotic center $A_{K}\left(\left\{x_{n}\right\}\right)=\{x\}$.

Let $\left\{u_{n}\right\}$ be any subsequence of $\left\{x_{n}\right\}$ with $A_{K}\left(\left\{u_{n}\right\}\right)=\{u\}$. It follows from (34) that

$$
\lim _{n \rightarrow \infty} d\left(u_{n}, T_{1} u_{n}\right)=0
$$

Now, we show that $u \in F\left(T_{1}\right)$. For this, we define a sequence $\left\{z_{n}\right\}$ in $K$ by $z_{k}=T_{1}^{k} u$. So, we calculate

$$
\begin{aligned}
& d\left(z_{k}, u_{n}\right) \\
& \leq d\left(T_{1}^{k} u, T_{1}^{k} u_{n}\right)+d\left(T_{1}^{k} u_{n}, T_{1}^{k-1} u_{n}\right)+\cdots+d\left(T_{1} u_{n}, u_{n}\right) \\
& \leq d\left(u, u_{n}\right)+\mu_{n} \phi_{1}\left(d\left(u, u_{n}\right)\right)+\xi_{n}+\sum_{i=1}^{k} d\left(T_{1}^{i} u_{n}, T_{1}^{i-1} u_{n}\right) \\
& \leq\left(1+\mu_{n} M^{*}\right) d\left(u, u_{n}\right)+\xi_{n}+\sum_{i=1}^{k} d\left(T_{1}^{i} u_{n}, T_{1}^{i-1} u_{n}\right) .
\end{aligned}
$$

Since $T_{1}$ is uniformly $L$-Lipschitzian, from (37) we have

$$
d\left(z_{k}, u_{n}\right) \leq\left(1+\mu_{n} M^{*}\right) d\left(u, u_{n}\right)+\xi_{n}+k L d\left(T_{1} u_{n}, u_{n}\right) .
$$

Taking limsup on both sides of the previous estimate and using (36), we have

$$
\begin{aligned}
r\left(z_{k},\left\{u_{n}\right\}\right) & =\limsup _{n \rightarrow \infty} d\left(z_{k}, u_{n}\right) \leq \limsup _{n \rightarrow \infty} d\left(u, u_{n}\right) \\
& =r\left(u,\left\{u_{n}\right\}\right) .
\end{aligned}
$$

Since $A_{K}\left(\left\{u_{n}\right\}\right)=\{u\}$, by the definition of asymptotic center $A_{K}\left(\left\{u_{n}\right\}\right)$ of a bounded sequence $\left\{u_{n}\right\}$ with respect to $K \subset$ $X$ and (8), this implies that $r\left(z_{k},\left\{u_{n}\right\}\right)=r\left(u,\left\{u_{n}\right\}\right)$, for all $k \geq 1$. Therefore, $\left|r\left(z_{k},\left\{u_{n}\right\}\right)-r\left(u,\left\{u_{n}\right\}\right)\right| \rightarrow 0$ as $k \rightarrow \infty$. It follows from Lemma 6 that $\lim _{k \rightarrow \infty} T_{1}^{k} u=u$. As $T_{1}$ is uniformly continuous, $T_{1} u=T_{1}\left(\lim _{k \rightarrow \infty} T_{1}^{k} u\right)=$ $\lim _{k \rightarrow \infty} T_{1}^{k+1} u=u$. That is, $u \in F\left(T_{1}\right)$. Similarly, we also can show that $u \in F\left(T_{2}\right)$. Hence, $u$ is the common fixed point of $T_{1}$ and $T_{2}$. Reasoning as previously mentioned by utilizing the uniqueness of asymptotic centers, we get that $x=u$. Since $\left\{u_{n}\right\}$ is an arbitrary subsequence of $\left\{x_{n}\right\}, A\left(\left\{u_{n}\right\}\right)=\{u\}$ for all subsequence $\left\{u_{n}\right\}$ of $\left\{x_{n}\right\}$. This proves that $\left\{x_{n}\right\} \Delta$-converges to a common fixed point of $T_{1}$ and $T_{2}$. This completes the proof. 
The following theorem can be obtained from Theorem 7 immediately.

Theorem 8. Let $K$ be a nonempty closed convex subset of a complete uniformly convex hyperbolic space $X$ with monotone modulus of uniform convexity $\eta$. Let $T_{i}: K \rightarrow K, i=$ 1,2 , be asymptotically nonexpansive mappings with sequence $\left\{t_{i n}\right\} \subset[1, \infty)$ satisfying $\lim _{n \rightarrow \infty} t_{i n}=1$. Assume that $F:=$ $\bigcap_{i=1}^{2} F\left(T_{i}\right) \neq \emptyset$; for arbitrarily chosen $x_{1} \in K,\left\{x_{n}\right\}$ is defined as follows:

$$
\begin{gathered}
x_{n+1}=W\left(x_{n}, T_{1}^{n} y_{n}, \alpha_{n}\right), \\
y_{n}=W\left(x_{n}, T_{2}^{n} x_{n}, \beta_{n}\right),
\end{gathered}
$$

where $\left\{t_{i n}\right\}, i=1,2,\left\{\alpha_{n}\right\}$ and $\left\{\beta_{n}\right\}$ satisfy the following conditions:

(1) $\sum_{n=1}^{\infty}\left(t_{\text {in }}-1\right)<\infty, i=1,2$;

(2) there exist constants $a, b \in(0,1)$ with $0<b(1-a) \leq$ $1 / 2$ such that $\left\{\alpha_{n}\right\} \subset[a, b]$ and $\left\{\beta_{n}\right\} \subset[a, b]$.

Then, the sequence $\left\{x_{n}\right\}$ defined in (40) $\Delta$-converges to a common fixed point of $F:=\bigcap_{i=1}^{2} F\left(T_{i}\right)$.

Proof. Take $\phi_{i}(t)=t, t \geq 0, \xi_{\text {in }}=0, \mu_{\text {in }}=t_{\text {in }}-1$ in Theorem 7. Since all conditions in Theorem 7 are satisfied, it follows from Theorem 7 that the sequence $\left\{x_{n}\right\} \Delta$-converges to a common fixed point of $F:=\bigcap_{i=1}^{2} F\left(T_{i}\right)$.

This completes the proof of Theorem 8 .

\section{Acknowledgments}

The authors would like to express their thanks to the editors and the referees for their helpful comments and suggestions. This work is supported by Scientific Research Fund of Sichuan Provincial Education Department (no. 11ZA222) and the Natural Science Foundation of Yibin University (no. 2012S07).

\section{References}

[1] U. Kohlenbach, "Some logical metatheorems with applications in functional analysis," Transactions of the American Mathematical Society, vol. 357, no. 1, pp. 89-128, 2005.

[2] P. K. F. Kuhfittig, "Common fixed points of nonexpansive mappings by iteration," Pacific Journal of Mathematics, vol. 97, no. 1, pp. 137-139, 1981.

[3] S. Reich and I. Shafrir, "Nonexpansive iterations in hyperbolic spaces," Nonlinear Analysis: Theory, Methods \& Applications, vol. 15 , no. 6, pp. 537-558, 1990.

[4] K. Goebel and S. Reich, Uniform Convexity, Hyperbolic Geometry, and Nonexpansive Mappings, Marcel Dekker, New York, NY, USA, 1984.

[5] M. R. Bridson and A. Haefliger, Metric Spaces of Non-Positive Curvature, Springer, Berlin, Germany, 1999.

[6] L. Leustean, "A quadratic rate of asymptotic regularity for CAT(0)-spaces," Journal of Mathematical Analysis and Applications, vol. 325, no. 1, pp. 386-399, 2007.

[7] S.-S. Chang, Y. J. Cho, and H. Zhou, "Demi-closed principle and weak convergence problems for asymptotically nonexpansive mappings," Journal of the Korean Mathematical Society, vol. 38, no. 6, pp. 1245-1260, 2001.

[8] S. S. Chang, L. Wang, H. W. J. Lee, C. K. Chan, and L. Yang, "Demiclosed principle and $\Delta$-convergence theorems for total asymptotically nonexpansive mappings in CAT( 0 ) spaces," Applied Mathematics and Computation, vol. 219, no. 5, pp. 26112617, 2012.

[9] H. Fukhar-ud-din and A. R. Khan, "Approximating common fixed points of asymptotically nonexpansive maps in uniformly convex Banach spaces," Computers \& Mathematics with Applications, vol. 53, no. 9, pp. 1349-1360, 2007.

[10] F. Gu and Q. Fu, "Strong convergence theorems for common fixed points of multistep iterations with errors in Banach spaces," Journal of Inequalities and Applications, vol. 2009, Article ID 819036, 12 pages, 2009.

[11] A. R. Khan, H. Fukhar-ud-din, and M. A. A. Khan, "An implicit algorithm for two finite families of nonexpansive maps in hyperbolic spaces," Fixed Point Theory and Applications, vol. 2012, p. 54, 2012.

[12] A. R. Khan, M. A. Khamsi, and H. Fukhar-ud-din, "Strong convergence of a general iteration scheme in CAT(0) spaces," Nonlinear Analysis: Theory, Methods \& Applications, vol. 74, no. 3, pp. 783-791, 2011.

[13] M. O. Osilike and S. C. Aniagbosor, "Weak and strong convergence theorems for fixed points of asymptotically nonexpansive mappings," Mathematical and Computer Modelling, vol. 32, no. 10, pp. 1181-1191, 2000.

[14] A. Şahin and M. Başarır, "On the strong convergence of a modified S-iteration process for asymptotically quasi-nonexpansive mappings in a CAT(0) space," Fixed Point Theory and Applications, vol. 2013, p. 12, 2013.

[15] J. Schu, "Weak and strong convergence to fixed points of asymptotically nonexpansive mappings," Bulletin of the Australian Mathematical Society, vol. 43, no. 1, pp. 153-159, 1991.

[16] J. Schu, "Iterative construction of fixed points of asymptotically nonexpansive mappings," Journal of Mathematical Analysis and Applications, vol. 158, no. 2, pp. 407-413, 1991.

[17] K.-K. Tan and H. K. Xu, "Fixed point iteration processes for asymptotically nonexpansive mappings," Proceedings of the American Mathematical Society, vol. 122, no. 3, pp. 733-739, 1994.

[18] Y. Yao and Y.-C. Liou, "New iterative schemes for asymptotically quasi-nonexpansive mappings," Journal of Inequalities and Applications, vol. 2010, Article ID 934692, 9 pages, 2010.

[19] L. Leuştean, "Nonexpansive iterations in uniformly convex $W$ hyperbolic spaces," in Nonlinear analysis and Optimization I. Nonlinear Analysis, B. S. Mordukhovich, I. Shafrir, and A. Zaslavski, Eds., vol. 513, pp. 193-209, American Mathematical Society, 2010. 


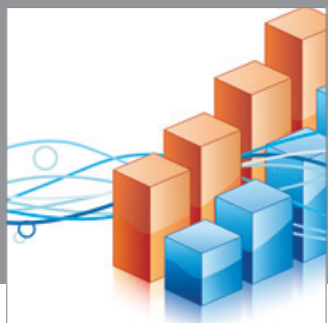

Advances in

Operations Research

mansans

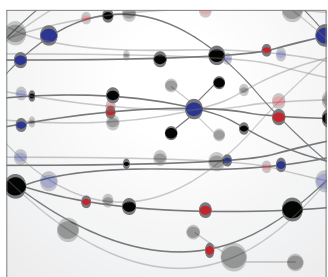

The Scientific World Journal
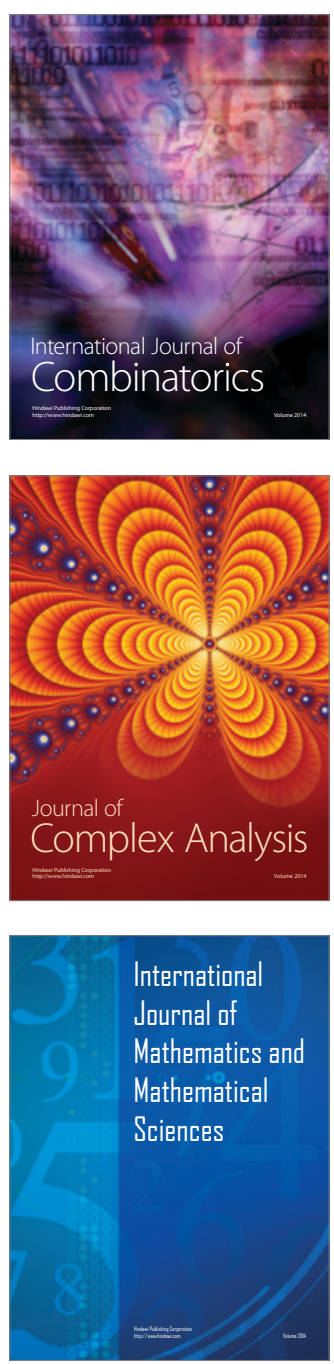
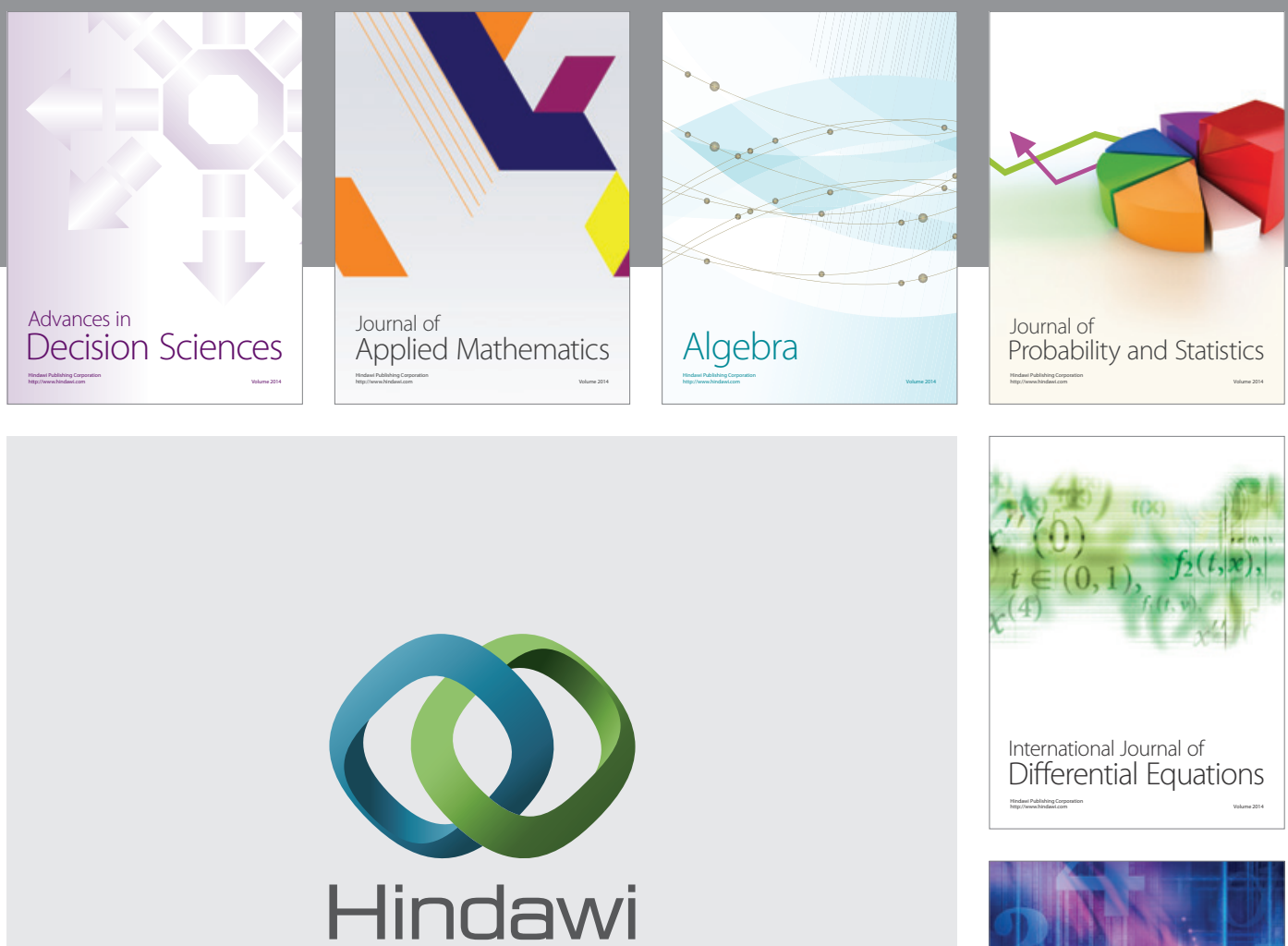

Submit your manuscripts at http://www.hindawi.com
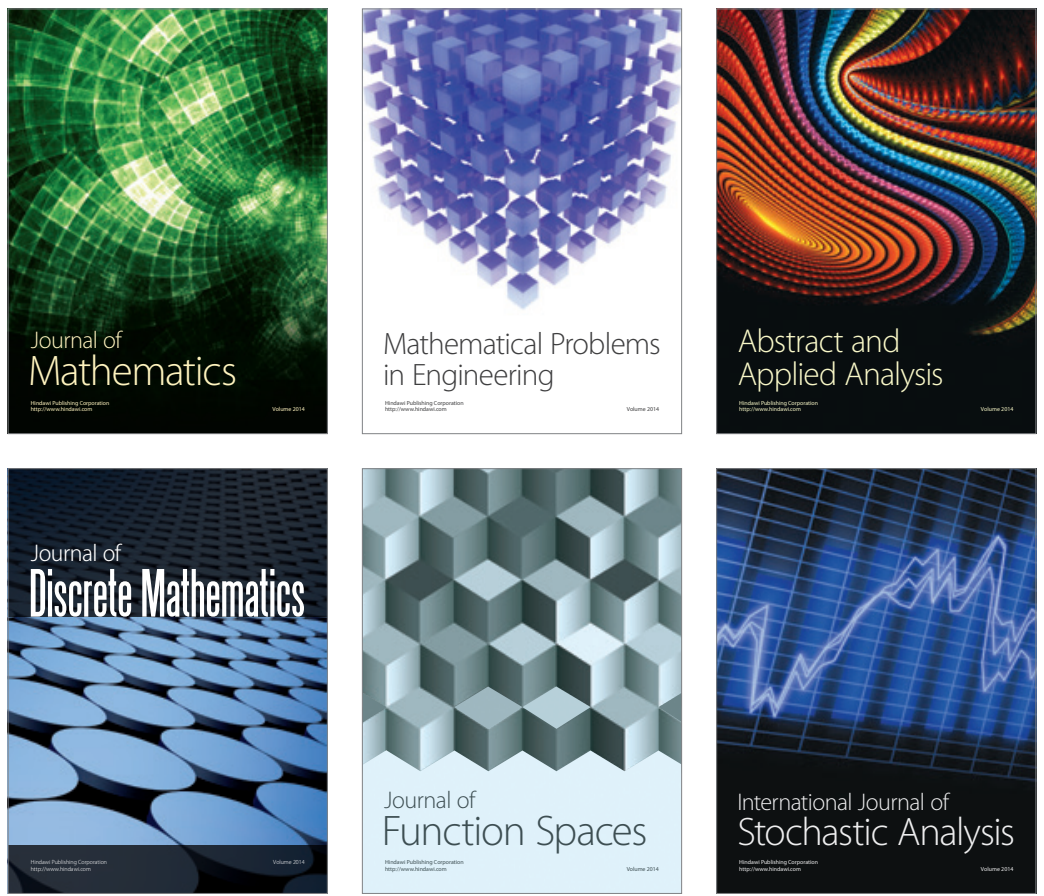

Journal of

Function Spaces

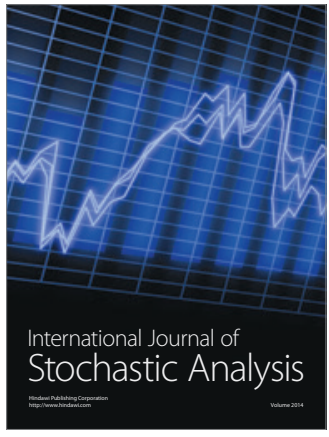

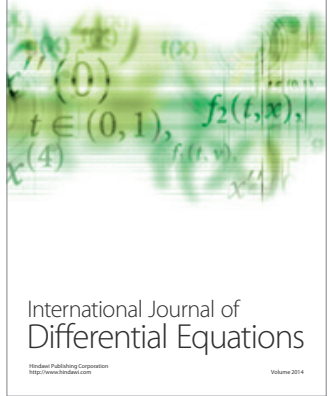
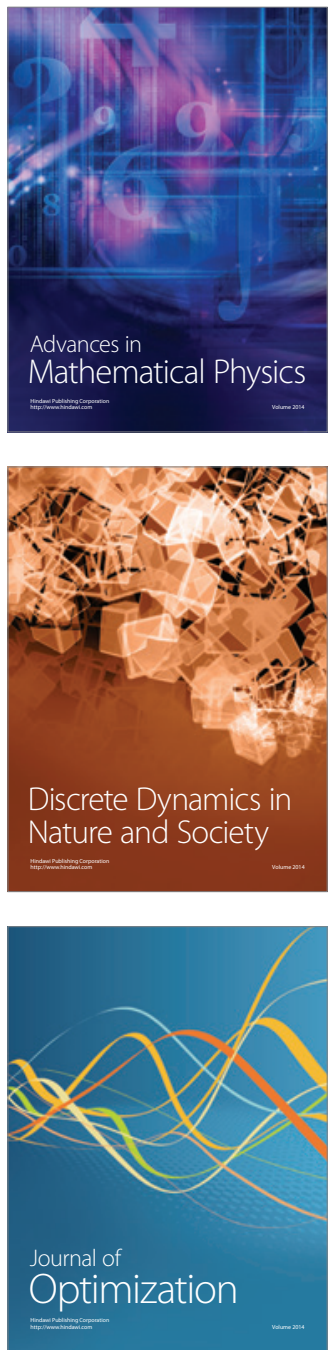